\title{
Standardization of Eclipta Alba by HPTLC, HPLC and AAS
}

Bhattacharjee $A^{1}$, Chakraborty $A^{2}$, Dutta $D^{1}$, Sau $A^{3}$, Chakraborty $S^{3}$, Samanta $N^{4}$, Biswas PS ${ }^{5}$ and Mukhopadhyay $G^{3^{*}}$

${ }^{1}$ Department of Pharmaceutical Sciences and Technology, Birla Institute of Technology, Mesra, Ranchi- 835215, India

${ }^{2}$ Department of Pharmaceutical Technology, Quality Assurance Executive in Cradel Pharmaceuticals Pvt. Ltd. Kolkata, W.B-700104, India

${ }^{3} B C D A$ College of Pharmacy and Technology, Kolkata, India

${ }^{4}$ Department of Pharmaceutical Technology, Jadavpur University, Kolkata, India

${ }^{5}$ Bharat Technology,Banitabla, Uluberia, Howrah, India

*Corresponding author: Mukhopadhyay G, Associate Professor, BCDA College of Pharmacy and Technology, Kolkata, W.B-700127, India, Tel: +91 9836333563. Email: gmukhopadhyay8@gmail.com

Received date: March 16, 2017; Accepted date: April 21, 2017; Published date: April 28, 2017

Copyright: (c) 2017 Mukhopadhyay G, et al. This is an open-access article distributed under the terms of the Creative Commons Attribution License, which permits unrestricted use, distribution, and reproduction in any medium, provided the original author and source are credited.

\begin{abstract}
The whole plant of bhringaraj (Eclipta alba) was dried and pulverized. The phytoconstituents of the pulverized plant material were extracted separately with two different solvents namely petroleum ether (hot percolation) and methanol (cold maceration) to carry out a comparative extraction efficiency of the above two solvents. $\beta$-sitosterol reported to have antiandrogenic, anticancer, antiinflammatory, antiprostatitic, antitumor, etc. activity, was selected as the active biomarker for quantification of the aforementioned plant material.

HPTLC was carried out for quantification of the biomarker and obtained data was compared with HPLC data. Petroleum ether was found to be an effective extracting solvent for $\beta$ sitosterol from $E$. alba as compared to methanol. The percentage content of $\beta$-sitosterol in $E$. alba methanolic and petroleum ether extract was found to be $0.10 \%$ and $4.65 \% \mathrm{w} / \mathrm{w}$ respectively by HPTLC whereas the percentage content of $\beta$-sitosterol in Eclipta alba petroleum ether extract was found to be $4.67 \% \mathrm{w} / \mathrm{w}$ by HPLC. AAS data revealed the presence of the metals (ppm \pm SEM) are within safety limits, copper $(1.151 \pm 0.031)$, chromium $(0.528 \pm 0.012)$, cadmium $(0.021 \pm 0.035)$, lead $(0.860 \pm 0.009)$, arsenic $(0.081 \pm 0.007)$, mercury $(0.036 \pm 0.010)$.
\end{abstract}

Keywords Eclipta Alba; HPTLC; HPLC; AAS; Standardization; Quantification

\section{Abbreviation}

HPTLC: High Performance Thin Layer Chromatography; HPLC: High Performance Liquid Chromatography; AAS: Atomic Absorption Spectrophotometer; $\mu \mathrm{g}$ : Microngram; mL: Mililitre; Rf: Retention Factor, $\mathrm{nm}$; Nanometer; $\mu \mathrm{L}$ : Microlitre; AA: Air acetylene flame

\section{Introduction}

Eclipta alba is a small branched perennial herb. The plant has a background of traditional medicinal uses in tropical and subtropical countries. It is commonly found in India, China, Taiwan, Philippines, Japan and Indonesia [1]. This herb has traditionally been used in ayurvedic medicine for being a liver tonic and having beneficial effects on diabetes, eye health, and hair growth.

Bhringaraj (Eclipta alba) oil is a well known hair tonic for keeping hair dark for regaining lost hair. It is also termed as 'king of the hair'. $E$. alba decocted in coconut oil, is referred as 'cooling' oil. It is used externally for 'hot' and inflammatory like headaches, sinusitis and ear infections. The herb is helpful in heat problems [2]. The whole plant of Eclipta alba works as a best medicine for hair growth. The presence of $\beta$-sitosterol in Eclipta alba help to rebuild hair in androgenic alopecia [3].

$\beta$-sitosterol is usually used for heart disease, modulating the immune system, prevention of cancer, as well as for rheumatoid arthritis, tuberculosis, hair loss and benign prostatic hyperplasia. Other activities recorded include trypanocidal and mosquito larvicidal, even neutralization of viper and cobra venom characteristics is also reported [4]. Standardization is an essential requisite for the establishment of a consistent biological activity or chemical profile of any plant product. Standardization, a tool in the quality control process thus, simply provides a quality assurance program for manufacturing of any herbal formulation.

For quality control of herbal materials or their extracts one needs to proceed by selecting one of the different phytoconstituents of the product, preferably the one showing maximum desired bioactivity and subsequent method of quantification of that specific constituent is required to be developed [5]. Presently standardization of herbal products has gained lot of interest. Simultaneous quantification of quercetin, $\beta$-sitosterol and linoleic acid in herbal hair gel has been reported earlier [6].

HPTLC as well as HPLC are modern adaptations of chromatography with better and advanced separation efficiency and detection limits. HPTLC can be utilized to identify as well as quantify the phytoconstituents, expected to be present in a medicinal plant. This is done from regulatory perspective to ensure the efficacy, quality as well safety of the herbal drugs present in a plant.

Presence of trace elements can be seen in medicinal plants. Low quantities of heavy metals like lead $(\mathrm{Pb})$, cadmium $(\mathrm{Cd})$, arsenic (As) and mercury $(\mathrm{Hg})$ are toxic for human health when exposed for a long time. According to World Health organization the maximum permissible levels in food and drug materials of heavy metals as given 
for cadmium $(\mathrm{Cd})$ and lead $(\mathrm{Pb})$ which are 0.3 and $10 \mathrm{mg} / \mathrm{kg}$ respectively [7].

\section{Materials and methods}

\section{Materials}

Equipments and reagents: CAMAG HPTLC system with automatic development chamber was used for quantification of phytoconstituents, details are as follows:

\section{Software: WINCATS}

\section{Automatic sample applicator: LINOMAT V}

Scanning densitometer: CAMAG scanner 3

Photo documentation apparatus: CAMAG reprostar-3

Stationary phase: Aluminum based silica gel plate $60 \mathrm{~F}_{254}$ (Merck, Mumbai) with $10 \mathrm{~cm} \times 10 \mathrm{~cm}$ in a particle size of 5-10 $\mu \mathrm{m} .100 \mu \mathrm{L}$ Syringe for sample application: (HAMILTON, Switzerland). RP-HPLC system (Shimadzu Prominence, Kyoto, Japan) with LC solution software was used for quantification of phytoconstituents, details are provided in table 1 .

The AAS system (AA 6300, Shimadzu, Japan) used was equipped with flame and graphite furnace having wavelength range of 185 to 900 $\mathrm{nm}$ and detector photo multiplier of 185.0 to $600.0 \mathrm{~nm}$. The solvents used in the study were of analytical grade. $\beta$-sitosterol was purchased from Sigma Aldrich. Methanol, acetonitrile and toluene (analytical grade) were purchased from Merck (Mumbai, India).

All the samples were filtered through Whatman's syringe filter $(0.45$ $\mu)$. Nitric acid $\left(\mathrm{HNO}_{3}\right)$, perchloric acid $\left(\mathrm{HClO}_{4}\right)$, hydrochloric acid $(\mathrm{HCl})$ and sulfuric acid $\left(\mathrm{H}_{2} \mathrm{SO}_{4}\right)$ were used and all were of analytical grade. The concentration of stock solution used in AAS like copper, chromium, cadmium, lead, arsenic, mercury was 1000 ppm. Metals used for AAS were obtained from Merck (Darmstadt, Germany).

The plant material was purchased from local plant nursery of Kolkata, West Bengal, India and the identity of the herb was confirmed by taxonomist. The phytoconstituents of the shade dried and pulverized plant material were extracted separately with two different solvents namely petroleum ether (hot percolation) and methanol (cold maceration). Rotary evaporator was utilized for drying the extract solution under reduced pressure.

\section{Methods}

\section{Standardization of $\beta$-sitosterol in Eclipta alba whole plant by HPTLC}

Preparation of standard solution: About $1 \mathrm{mg}$ of $\beta$-sitosterol standard was taken in a eppendorf tube $(1 \mathrm{~mL}) .1 \mathrm{~mL}$ of methanol was added to it and mixed by vortexing mixture to dissolve the material completely.

\section{Preparation of sample solution}

About $10.1 \mathrm{mg}$ of lyophilized methanolic and $5 \mathrm{mg}$ of petroleum ether extract of Eclipta alba (whole plant) was taken in two separate 1 $\mathrm{mL}$ of eppendorf tubes. $1 \mathrm{~mL}$ of methanol was added to the methanolic extract and $1 \mathrm{~mL}$ of petroleum ether was added to the petroleum ether extract of Eclipta alba.
For dissolving the materials the samples were subjected to vortexing followed by ultrasonication. Samples were filtered through $0.45 \mu$ syringe filter and kept for further study. Flowchart describing the abovementioned procedure is given in figure 1 .

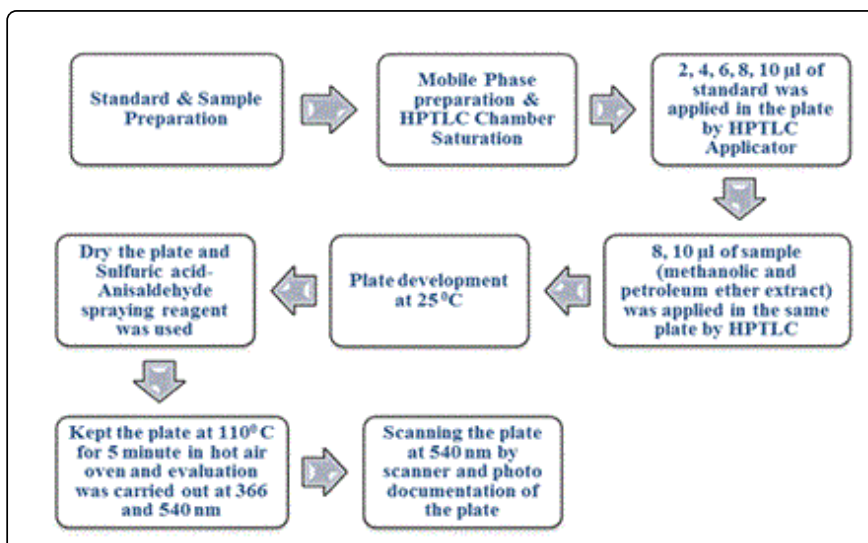

Figure 1: Standardization of $\beta$-sitosterol (standard) in Eclipta alba whole plant by HPTLC.

\section{Chromatographic conditions}

HPTLC analysis was performed using isocratic technique. Mobile phase was optimized with toluene and methanol in a ratio of 9:1 v/v. The temperature was maintained at $25^{\circ} \mathrm{C}$ and mobile phase was developed in a twin trough glass chamber. Standard stock solution was applied consequently in the range of $2-10 \mu \mathrm{L}$ with $2 \mu \mathrm{L}$ gradual increment.

Methanolic and petroleum ether extract of Eclipta alba (whole plant) was applied 8 and $10 \mu \mathrm{L}$ each at the concentration $10 \mathrm{mg} / \mathrm{mL}$ and $5 \mathrm{mg} / \mathrm{mL}$ respectively. All total 9 tracks in HPTLC plate were used for standardization including standard and sample solution respectively in a band wise fashion.

After development, plates were air dried. The dry plate was treated with sulfuric acid-anisaldehyde spraying reagent. The plate was kept at $110^{\circ} \mathrm{C}$ for $5 \mathrm{~min}$ in hot air oven and evaluation was carried out at 366 and $540 \mathrm{~nm}$. Colored bands were observed at $540 \mathrm{~nm}$.

\section{Standardization and quantification of $\beta$-sitosterol in Eclipta alba by HPLC}

Preparation of standard solution: About $1 \mathrm{mg}$ of $\beta$-sitosterol standard was taken in a $1 \mathrm{~mL}$ eppendorf tube, $1 \mathrm{~mL}$ of methanol was added to it and mixed in vortex mixture. Volume was made with methanol to obtain standard stock solution of concentration 1000 $\mu \mathrm{g} / \mathrm{mL}$. Further dilutions were made as required with methanol for calibration curve shown in figure 2.

Preparation of sample solution: About $1 \mathrm{mg}$ of Eclipta alba petroleum ether extract was taken in a eppendorf tube and $1 \mathrm{~mL}$ of petroleum ether was added to it. The sample was vortexed for $15 \mathrm{~min}$ and then subjected to ultrasonication for $30 \mathrm{~min}$. The solution was then filtered through $0.45 \mu$ syringe filter. The concentration of sample solution obtained was $1000 \mu \mathrm{g} / \mathrm{mL}$.

Chromatographic conditions: HPLC analysis was performed using isocratic technique. HPLC method parameters are given in table 1. 
Page 3 of 6

\begin{tabular}{|c|c|c|}
\hline HPLC System & & $\begin{array}{l}\text { Shimadzu HPLC with rheodyne injector (loop size of } \\
20 \mu \mathrm{L} \text { ). }\end{array}$ \\
\hline Pump & & $\begin{array}{l}\text { Binary pump. Reciprocating pumps (Shimadzu } \\
\text { LC-20 AD UFLC) }\end{array}$ \\
\hline Detector & & PDA Multi-wavelength detector.(Shimadzu SPDM20A) \\
\hline Stationary phase & & $\begin{array}{l}\text { RP- } C_{18}(250 \mathrm{~mm} \times 4.6 \mathrm{~mm} \text { i.d., particle size } 5 \mu \mathrm{m}) \\
\text { column. (Phenomenex-Luna } \mathrm{C}_{18} \text {, Torrance, CA, } \\
\text { USA). }\end{array}$ \\
\hline Mobile phase & : & Acetonitrile: Methanol $(7: 3 \mathrm{v} / \mathrm{v})$. \\
\hline Detection wavelength & 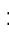 & UV detector, $210 \mathrm{~nm}$. \\
\hline Flow rate & & $1 \mathrm{~mL} / \mathrm{min}$. \\
\hline $\begin{array}{l}\text { Syringe for sample } \\
\text { injection }\end{array}$ & 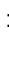 & $100 \mu \mathrm{L}$ (HAMILTON, Switzerland). \\
\hline Sample size & : & $20 \mu \mathrm{L}$. \\
\hline Temperature & & $25^{\circ} \mathrm{C}$ \\
\hline
\end{tabular}

Table 1: HPLC Method Parameters.

\section{Atomic absorption spectroscopy (AAS) study of trace and heavy metal analysis of plant material}

Sample preparation: For the analysis, plant sample was ground to a fine powder and dried at 55 to $70^{\circ} \mathrm{C}$ for $6-8 \mathrm{~h}$ in a controlled environment, to remove moisture. Immediately after drying, accurately weighed $1.0 \mathrm{~g}$ was placed in a flask and treated with $12 \mathrm{~mL}$ of concentrated $\mathrm{HNO}_{3}$ for $24 \mathrm{~h}$. About $5 \mathrm{~mL}$ of a mixture of $\mathrm{H}_{2} \mathrm{SO}_{4}$ and $\mathrm{HNO}_{3}(3: 1)$ was added to each of the conical flask. The mixture was then heated at $120-130^{\circ} \mathrm{C}$ for $5-6 \mathrm{~h}$, until evolution of fumes stopped and the resulting solution turned to be clear. It was then cooled at room temperature and filtered using Whatman filter paper no. 42.

The entire filtrate was mixed and the volume was made up to $50 \mathrm{~mL}$ with Milli-Q water. A blank was also prepared for every sample in the same way but with the plant sample being absent. Each sample was aspirated twice and the experiment was repeated for five times. The concentration of stock solution used in AAS like copper, chromium, cadmium, lead, arsenic, mercury was $1000 \mathrm{ppm}$. From the aforementioned stock solution, the concentration of working ranges as mentioned in table 2 was prepared. Instrumental condition for trace and heavy metal analysis also given in same aforesaid table.

\begin{tabular}{|c|c|c|c|c|c|c|}
\hline Elements & & & & & & \\
\hline $\begin{array}{l}\text { AAS } \\
\text { specifica } \\
\text { tion }\end{array}$ & Copper & Chromium & Cadmium & Arsenic & Lead & Mercury \\
\hline $\begin{array}{l}\text { Wavelen } \\
\text { gth }\end{array}$ & 324.8 & 357.9 & 232.0 & 193.7 & 217.0 & 253.7 \\
\hline $\begin{array}{l}\text { Current } \\
(\mathrm{mA})\end{array}$ & 5.0 & 5.0 & 9.0 & 12.0 & 9.0 & 3.0 \\
\hline Flame & AA & AA & $\mathrm{AA}$ & $\mathrm{AA}$ & AA & $A A$ \\
\hline $\begin{array}{l}\text { Fuel } \quad(L / \\
\text { min) }\end{array}$ & 3.05 & 2.90 & 2.94 & 2.40 & 2.90 & 7.66 \\
\hline
\end{tabular}

\begin{tabular}{|l|l|l|l|l|l|l|}
\hline $\begin{array}{l}\text { Slit width } \\
(\mathrm{nm})\end{array}$ & 0.5 & 0.5 & 0.5 & 0.5 & 0.5 & 0.5 \\
\hline $\begin{array}{l}\text { Working } \\
\text { range } \\
(\mathrm{ppm})\end{array}$ & $0.5-5$ & $0.5-5$ & $0.5-5$ & $0.04-0.1$ & $0.5-5$ & $1-0.2$ \\
\hline $\begin{array}{l}\text { Read } \\
\text { time } \\
(\mathrm{sec})\end{array}$ & 3 & 3 & 3 & 3 & 3 & 3 \\
\hline $\begin{array}{l}\text { Wash } \\
\text { time } \\
(\mathrm{sec})\end{array}$ & 10 & 10 & 10 & 10 & 10 & 10 \\
\hline
\end{tabular}

Table 2: Instrumental condition for trace and heavy metal analysis by atomic absorption spectrometry.

\section{Results and discussions}

\section{Standardization and quantification of $\beta$-sitosterol in Eclipta alba by HPTLC}

The percentage content of $\beta$-sitosterol in Eclipta alba methanolic and petroleum ether extract was found to be $0.10 \%$ and $4.65 \%$ respectively. This was determined by a calibration curve with the equation of $\mathrm{Y}=3447.759^{\star} \mathrm{X}-1121.100$ (correlation coefficient $=0.9686$ and standard deviation $= \pm 5.20 \%$ ) as shown in figure 2 where $X$ represents amount of $\beta$-sitosterol and Y represents area under the curve.

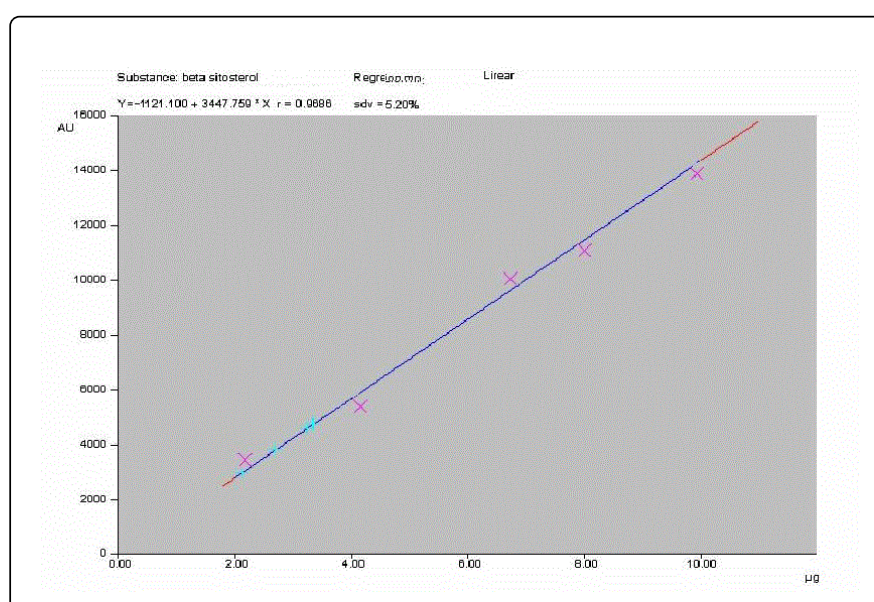

Figure 2: HPTLC Calibration curve of $\beta$-sitosterol.

$\mathrm{Rf}$ value of standard $\beta$-sitosterol was found to be 0.66 . Specificity was confirmed by comparing the Rf of standard and sample (Figure 3, $4 \& 5)$.

Photodocumentaton of $E$. alba whole plant extract at $366 \mathrm{~nm}$ and $540 \mathrm{~nm}$ is given in figure 6 and 7 respectively. 3D Chromatogram of $E$. alba extract and standard $\beta$-sitosterol at $540 \mathrm{~nm}$ is depicted in figure 8 . 


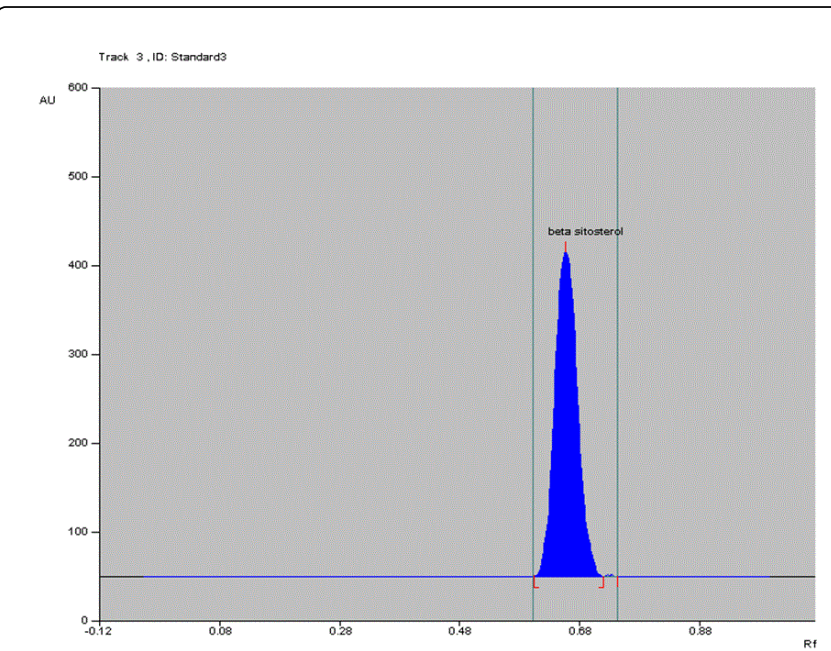

Figure 3: HPTLC chromatogram of standard $\beta$-sitosterol.

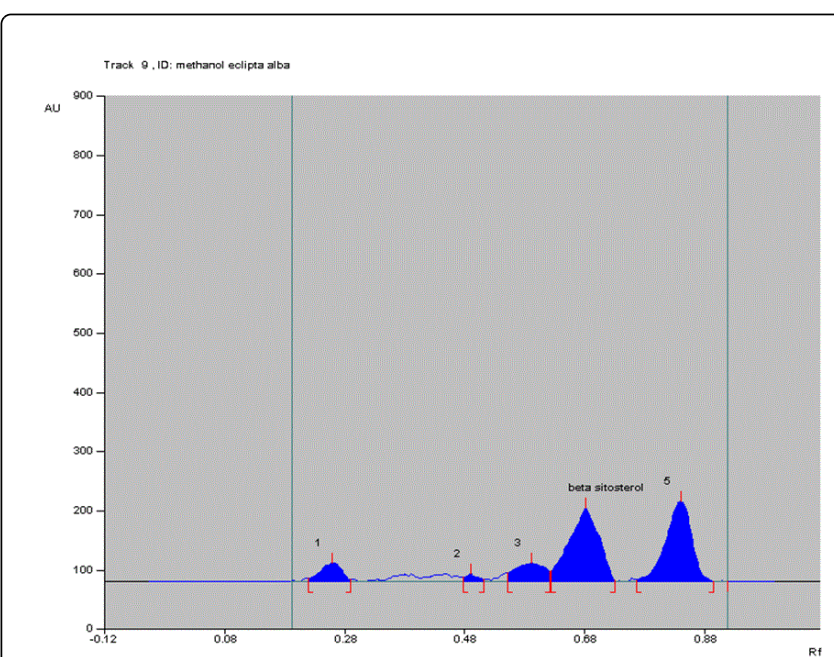

Figure 4: HPTLC chromatogram of methanolic extract of Eclipta alba.

\section{Standardization and quantification of $\beta$-sitosterol in Eclipta alba by HPLC}

The percentage content of $\beta$-sitosterol in Eclipta alba petroleum ether extract was found to be $4.67 \% \mathrm{w} / \mathrm{w}$. This was determined by a calibration curve with the equation of $\mathrm{Y}=2649.8^{*} \mathrm{X}+228397$ (correlation coefficient $=0.9923$ as shown in figure 9 where $\mathrm{X}$ represents amount of $\beta$-sitosterol and $\mathrm{Y}$ represents area under the curve. Retention time (Rt) value of standard $\beta$-sitosterol was found to be $2.325 \mathrm{~min}$. Specificity was confirmed by comparing the Rt of standard and sample (Figure 10-11).

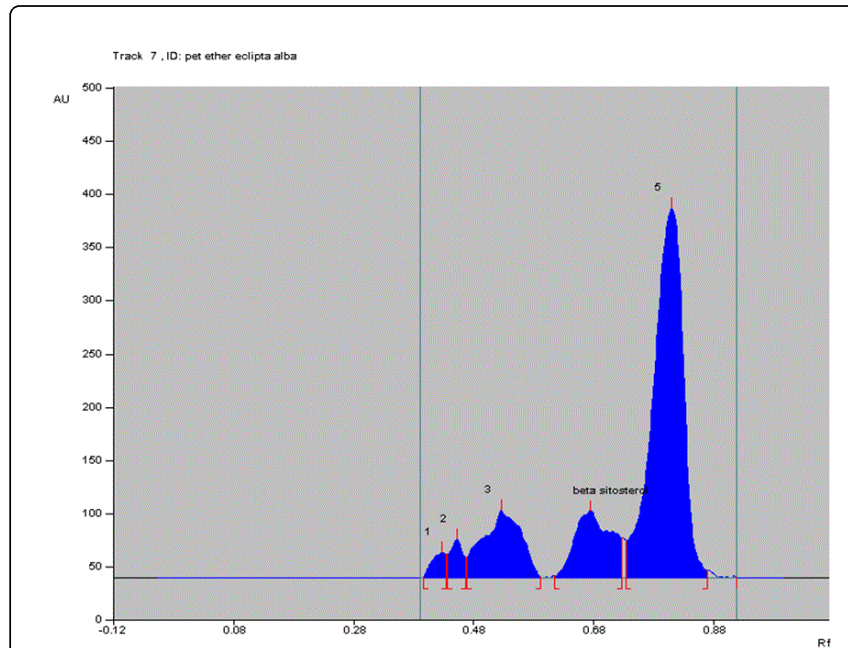

Figure 5: HPTLC chromatogram of petroleum ether extract of Eclipta alba.

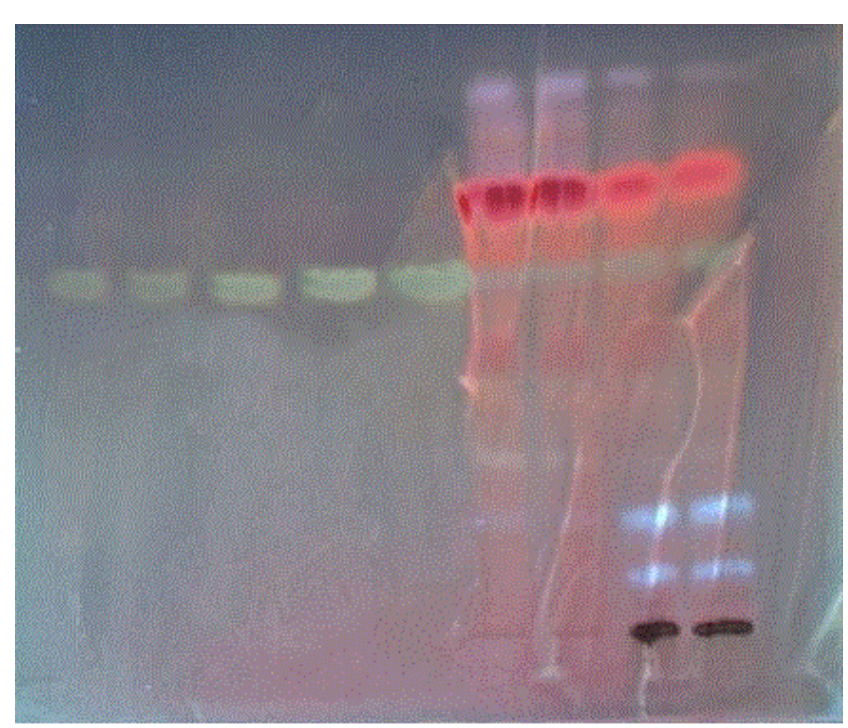

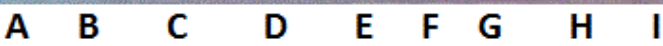

Figure 6: Photodocumentaton of Eclipta alba whole plant extract at $366 \mathrm{~nm}$. Track number A-E represents standard $\beta$-sitosterol, F-G and H-I represent petroleum ether and methanolic extract of Eclipta alba. 


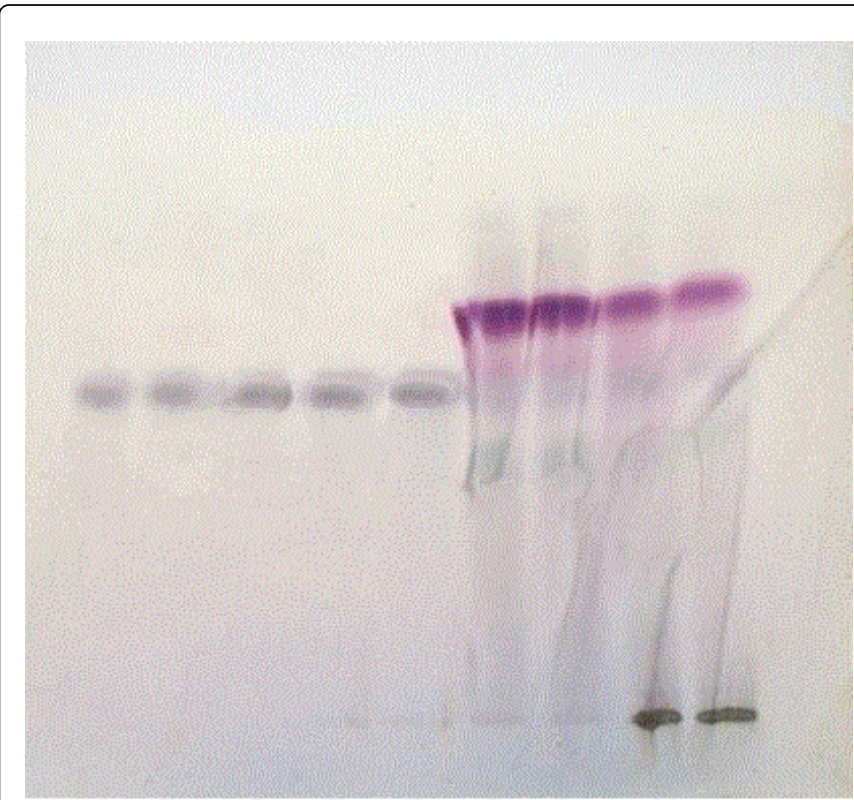

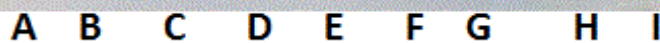

Figure 7: Photodocumentaton of Eclipta alba whole plant extract at $540 \mathrm{~nm}$. Track number A-E represents standard $\beta$-sitosterol, F-G and $\mathrm{H}-\mathrm{I}$ represent petroleum ether and methanolic extract of Eclipta alba.

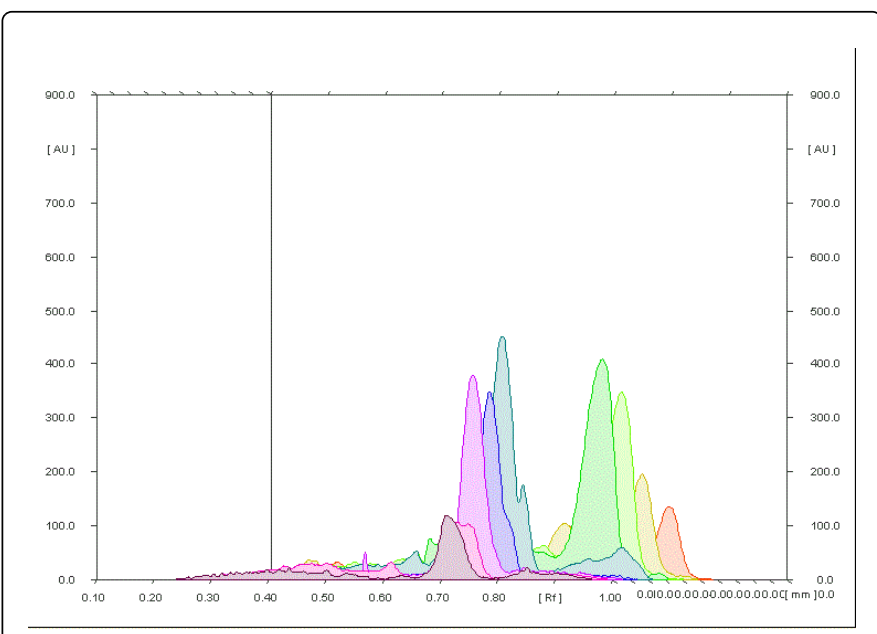

Figure 8: 3D Chromatogram of Eclipta alba and standard $\beta$ sitosterol at $540 \mathrm{~nm}$.

\section{Atomic absorption spectroscopy (AAS) study of heavy and trace metal analysis of plant material}

The data were represented as the mean \pm SEM using the Graph-Pad Prism Version 6.0 on the basis of the number of samples analyzed. The concentration of the trace and heavy metals obtained in plant material was expressed in terms of parts per million. The concentration of the different elements found is shown in table 3 . The levels of heavy and trace metals quantified in the plant sample were found within prescribed limits.

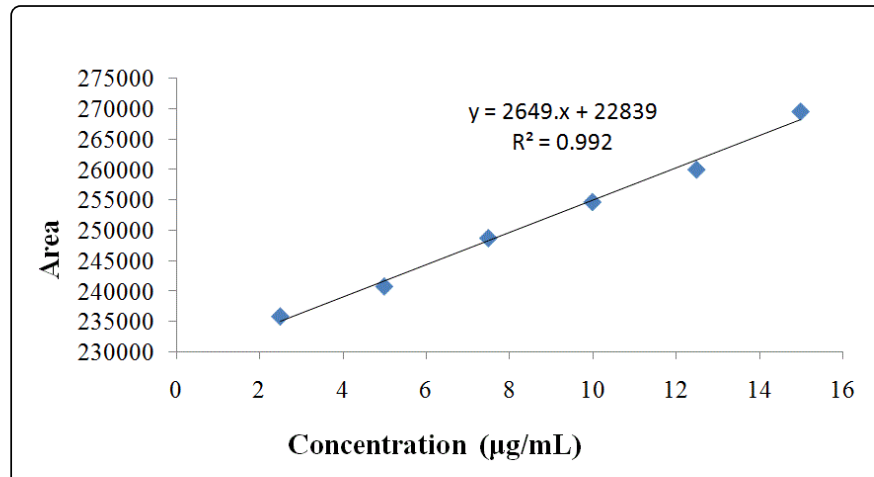

Figure 9: Calibration curve of $\beta$-sitosterol.

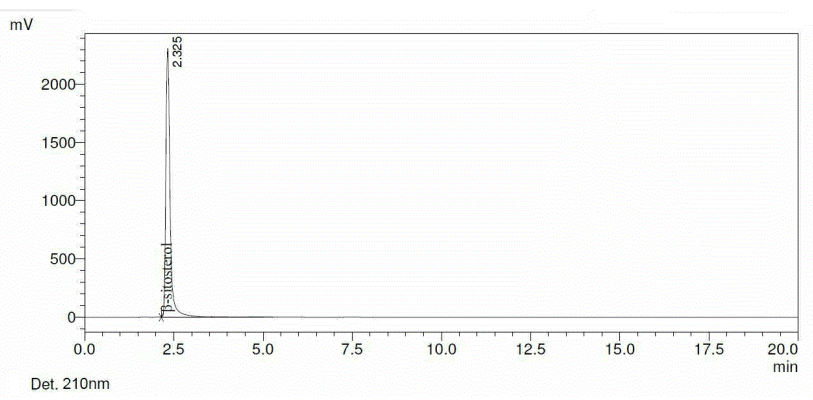

Figure 10: Chromatogram of $\beta$-sitosterol by HPLC.

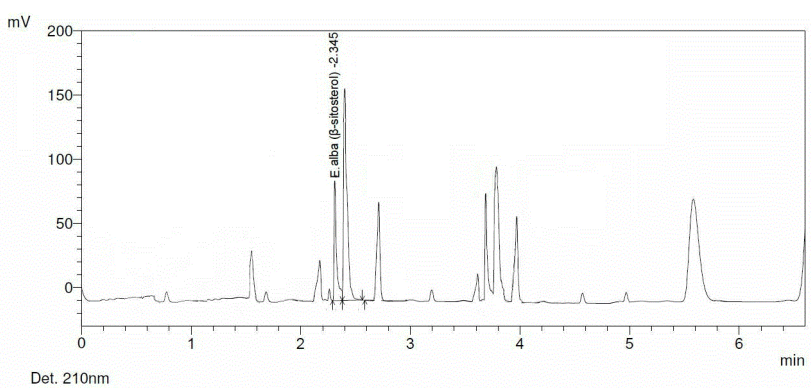

Figure 11: Chromatogram of Eclipta alba petroleum ether extract by HPLC.

\begin{tabular}{|c|c|c|c|c|c|c|}
\hline $\begin{array}{l}\text { Plant } \\
\text { used }\end{array}$ & $\begin{array}{l}\text { Copper } \\
\text { (ppm } \\
\pm \text { SEM) }\end{array}$ & $\begin{array}{l}\text { Chromium } \\
\text { (ppm } \\
\pm \text { SEM) }\end{array}$ & $\begin{array}{l}\text { Cadmium } \\
\text { (ppm } \\
\pm \text { SEM) }\end{array}$ & $\begin{array}{l}\text { Lead } \\
\text { (ppm } \\
\pm \text { SEM) }\end{array}$ & $\begin{array}{l}\text { Arsenic } \\
\text { (ppm } \\
\pm \text { SEM) }\end{array}$ & $\begin{array}{l}\text { Mercury } \\
\text { (ppm } \\
\pm \text { SEM) }\end{array}$ \\
\hline $\begin{array}{l}\text { Eclipta } \\
\text { alba }\end{array}$ & $\begin{array}{l}1.151 \pm \\
0.031\end{array}$ & $\begin{array}{ll}0.528 & \pm \\
0.012 & \end{array}$ & $\begin{array}{l}0.021 \\
0.035\end{array}$ & $\begin{array}{l}0.860 \pm \\
0.009\end{array}$ & $\begin{array}{l}0.081 \pm \\
0.007\end{array}$ & $\begin{array}{l}0.036 \quad \pm \\
0.010\end{array}$ \\
\hline
\end{tabular}

Table 3: Result of trace and heavy metal analysis by atomic absorption spectrometry.

\section{Conclusion}

For the extraction of $\beta$-sitosterol from $E$. alba whole plant petroleum ether proved to be a superior solvent as compared to methanol. HPLC and HPTLC data as obtained were closely related and these methods 
Citation: Bhattacharjee A, Chakraborty A, Dutta D, Mukhopadhyay G (2017) Standardization of Eclipta Alba by HPTLC, HPLC and AAS. Pharm Anal Acta 8: 541. doi:10.4172/2153-2435.1000541

Page 6 of 6

can be used for standardization purpose of the plant as well as its formulations. AAS study reveals that arsenic and toxic metals are within national limits. It can be expected that the mentioned HPLC \& HPTLC techniques may be applied successfully for standardization of $\beta$-sitosterol as marker in different herbal extracts and formulations and AAS may be utilized for evaluation of toxic metals.

\section{References}

1. Mahmood S, Hussain S, Malik F (2013) Accentuating the prodigious significance of Eclipta alba-An inestimable medicinal plant. Pak J Pharm Sci 26: 1259-1266.

2. Caldecott T, Tierra M (2006) Ayurveda: The divine science of life. Elsevier Health Sciences.
3. Roy RK, Thakur M, Dixit VK (2008) Hair growth promoting activity of Eclipta alba in male albino rats. Arch Dermatol Res 300: 357-364.

4. Saeidnia S, Manayi A, Gohari AR, Abdollahi M (2014) The Story of Betasitosterol-A Review. Euro J Med Plants 4: 590-609.

5. Chakraborty A, Bhattacharjee A, Dasgupta P, Manna D, Chun WOH, et al. (2016) Simple Method for Standardization and Quantification of Linoleic Acid in Solanum nigrum Berries by HPTLC. J Chromatogr Sep Tech 7: 342.

6. Chakraborty A, Bhattacharjee A, Sodani A, Jain D, Mukhopadhyay G, et al. (2016) Herbal Hair Gel Formulation having 5 a-Reductase Inhibitory Activity and its Standardization by HPTLC. J Anal Bio anal Tech 7: 341.

7. WHO (2007) WHO guidelines for assessing quality of herbal medicines with reference to contaminants and residues, World Health Organization. 